Supervisor-nurse relationships, teamwork, role ambiguity and wellbeing: public versus private sector nurses

Yvonne Brunetto BA, DipED, PhD

Associate Professor in HRM

School of Commerce and Management,

Southern Cross University

Email: yvonne.brunetto@scu.edu.au

Rod Farr-Wharton B.Sc, M.Sc. PhD

University of the Sunshine Coast,

Maroochydore, Queensland. 4558, AUSTRALIA

Email: rfarr@usc.edu.au

Kate Shacklock B.Ec, PhD

Department of Employment Relations and Human Resources,

Griffith University - Gold Coast campus

Southport 4222, Queensland, AUSTRALIA

Email: k.shacklock@griffith.edu.au

\title{
Correspondence:
}

yvonne.brunetto@scu.edu.au 


\title{
Supervisor-Nurse Relationships, Teamwork, Role Ambiguity and Wellbeing: public versus private sector nurses
}

\begin{abstract}
This paper uses a Leader-Member Exchange theoretical framework to compare the relationship of the supervisor-subordinate relationship upon nurses' satisfaction with teamwork and their perceived levels of role ambiguity, and in turn, their perceptions of wellbeing. Data were collected using a survey-based, self-report strategy from 1138 nurses, of which 901 worked in private sector hospitals and 237 were from the public sector.

Using path analysis, the findings from this study identify that supervisor-nurse relationships affect nurses' perceptions of teamwork, role ambiguity and wellbeing, although the association is different for public sector compared with private sector nurses. However, of the two groups, private sector nurses were the most satisfied with their supervisor-nurse relationship and teamwork, and had higher perceived levels of both role clarity (instead of role ambiguity) and consequent wellbeing.
\end{abstract}

Key words: Leader-member exchange (LMX), nurses, teamwork, wellbeing, Australia, 


\section{Supervisor-Nurse Relationships, Teamwork, Role Ambiguity and Wellbeing: public versus private sector nurses}

There is a shortage of nurses in Australia, affected by decreased nurse supply due to the aging population, inadequate numbers attracted to the profession and high turnover (Buchan and Calman 2004). In Australia, approximately one-quarter of nurses are currently working in other occupations (ABS 2005), women tend to retire early (on average aged 48 years) (ABS 2009) and two thirds of Australian nurses are currently aged between mid 40s and 65 years (Bell and Narz 2007). The retention situation is therefore vital to healthcare managers.

Yet, previous research has found that effective workplace relationships positively enhance retention (Cropanzano and Mitchell 2005; Hodson 2004). Nurses, similarly to other employees, are likely to experience numerous workplace relationships including with their supervisors and colleagues in the same team (Masterson et al, 2000) and notably, workplace relationships are especially vital for women's intentions to continue working (Shacklock, Brunetto and Nelson 2009). Research by Rodwell et al (2009) suggests that the nurse supervisor is instrumental in predicting nurses' levels of job satisfaction, organisational commitment and wellbeing. The supervisor-subordinate relationship was also the factor most likely to improve commitment to the organisation (Brunetto, Farr-Wharton and Shacklock 2010) and retention (Cohen 2006; Tauton, et al 1997). Hence, the supervision practices used in wards is critical in determining outcomes for nurses.

One way of examining the supervisor-subordinate relationship is by using a LeaderMember Exchange (LMX) theoretical lens. LMX theory argues that supervisors manage employees differently, and consequently, different outcomes occur for different groups of employees. Depending on the quality of 'social exchanges' between supervisors and subordinates, either an effective (high quality) or an ineffective (low quality) LMX 
relationship develops (Gerstner and Day 1997; Mueller and Lee 2002). The high quality LMX group receives access to information, support and participation in decision-making, making it easier for them to undertake tasks and solve work-related problems. High quality LMX also promotes knowledge-sharing and participation in decision-making within teams (Birdi et al 2008), likely decreasing role ambiguity associated with reduced levels of 'nearmisses' and/or harmful errors (Dawson, West and Yan 2008). By comparison, the low quality LMX group is poorly serviced by their supervisors. Hence, the LMX relationship is expected to be a key to the quality of teamwork and in turn, the role ambiguity in relation to patients experienced by nurses.

However, there is a lack of consensus as to whether the management of nurses is similar across public and private sector hospitals. On the one hand, it is likely that, irrespective of the sector, nurses in acute clinical settings will experience similar clinical work and a comparable patient case mix, especially since recent reforms have led to publicprivate partnerships and contracting out of beds, such that some private hospitals provide services to public patients and vice versa. This process may have blurred the sharp distinctions across public and private/non profit hospitals (Brown and Barnett 2004). On the other hand, Steane (1997) argues that there are differences in the core values of hospitals across public and private/non profit hospitals and this could result in subtle differences in management practices across the sector. Within Australia, approximately 60 percent of acute hospital beds are public sector and it is unclear whether nurse supervision practices (particularly the quality of exchanges) in public hospitals are the same as those in private and non-profit hospitals.

This paper compares the association of the supervisor-subordinate relationship with nurses' satisfaction with teamwork and their perceived levels of patient role ambiguity, and in turn upon their perceptions of wellbeing. These issues are important because past research 
suggests that the quality of supervision affects subordinates' access to information, resources and support (Gerstner and Day 1997; Mueller and Lee 2002), thereby affecting the quality of teamwork (Birdi et al 2008) and, consequently, the degree to which nurses experience role ambiguity leading to 'near-misses'/errors (Dawson, et al 2008). Moreover, whilst there is research linking the quality of the supervisor-subordinate relationship with perceptions of wellbeing (Gerstner and Day 1997; Judge and Watanabe 1993), it is unclear whether the combination of the quality of supervision and teamwork and perceptions of patient role ambiguity affect nurses' perceptions of wellbeing. The research questions guiding data collection are:

RQ1: What is the association between the supervisor-subordinate relationship and nurses' perceptions of teamwork, and in turn role ambiguity in relation to the patient and wellbeing?

RQ2: Is the association the same for public and private sector nurses between the supervisorsubordinate relationship and perceptions of teamwork, patient role ambiguity and in turn, wellbeing?

This paper has four parts. The first part provides a targeted review of the literature from which the hypotheses emerge. The second part describes the sample and methods used to test the hypotheses and address the research questions. The third part reports the results and uses the discussion section to identify pattern-matching with relevant past research and implications for healthcare managers. Finally, the paper concludes and offers suggestions for future research.

\section{Leader-Member Exchange Theory}

As stated, the basis of Leader-Member Exchange (LMX) theory is that supervisors manage employees differently, and consequently, different groups of employees experience different outcomes. The 'in-group’ experiences high levels of mutual support, trust and 
respect along with increased access to information, support and participation in decisionmaking (Gerstner and Day 1997; Mueller and Lee 2002) plus access to meaningful feedback and delegated decision-making and power (Wayne, Shore and Linden 1997; Yrie, Hartman and Galle 2003). As a result, in-group employees are likely to receive promotions, bonuses and/or intangible benefits such as interesting work assignments plus greater control over workloads (Yukl 2006). It seems likely that employees who perceive that their supervisors' support them are also more likely to display support towards their supervisors in return (Podsakoff, et al 2000; Wayne et al. 1997). The outcome for patients is positive because such supported employees find it easier to undertake tasks and solve work-related problems.

Hence, using LMX theory, it is expected that the quality of the supervisor-subordinate relationship will affect the quality of teamwork and in turn, the level of role ambiguity in relation to patients, because it affects nurses' access to information, resources, support and the extent to which participatory decision-making is used. These very same factors are consequently likely to affect nurses’ perceptions of wellbeing. In contrast, a poor supervisorsubordinate relationship is likely to involve mixed messages from supervisors along with poor flows of information and resources. These latter conditions are ripe for creating poor teamwork experiences, likely to lead to increased ambiguity when nurses service their patients. However, the relationships between these factors remain under-researched and therefore, this area needs investigation.

\section{Supervisor-Subordinate Relationship}

The LMX concept is useful to examine within the healthcare sector because, recent reforms have specifically aimed to curb the power of public sector professionals by increasing their accountability (Ackroyd et al 2007). However, nurses' perceptions of power are dependent somewhat on the ability of supervisors to mediate organisational management 
goals (Ackroyd, et al 2007). Hoggett (1994) argues that for public sector professionals such as nurse supervisors, the strategy has not been to attempt to directly control nurses; instead, it has been to convert nurse supervisors into managers, thereby placing the responsibility for achieving organisational goals (typically efficiency objectives related to "doing more with less”) on them. They have then been expected to use their position to ensure that their nurses achieve organisational goals (Avis 1996).

As a consequence, public sector nurses in countries such as the UK, USA, NZ and Australia have experienced standardization in service delivery, based on resource utilization, with resultant work intensification (Ackroyd, et al 2007). In particular, public sector nurses have experienced increased workloads, poorer working conditions, inflexible scheduling, increased intensity of work, loss of work autonomy and increased accountability - especially in relation to increased record-keeping and data collection (Adcroft and Willis 2005; Brunetto and Farr-Wharton 2005, 2006, 2007; Buchanan and Considine 2002; Newman, et al 2002). To some extent, supervisors have had to invoke their managerial power and increase nurses' levels of accountability because of the performance indicators imposed on them by higher levels of management (Butterfield, Edwards and Woodall 2005). The outcome for nurse managers has been that they are expected to create empowering social environments while simultaneously operating within "tight budgetary controls and performance measures and targets” that override all other goals (Bolton 2003: 126). However, Coyle-Sharpiro (1999) argues that many supervisors have actively embraced their increased managerial power at the expense of employees. These new conditions are likely to have affected the supervisor-nurse relationship for public sector nurses. Hence the supervisor-nurse relationship in the public sector has changed and it is therefore likely that public sector nurses now experience a lower level of satisfaction with their supervisors compared with private sector nurses. 


\section{Teamwork}

A team is described as a group of interdependent workers, often with complementary skills, who share a common goal and have the potential for high performance (Katzenbach and Smith 1993). However, achieving high performance is dependent on the team's ability to go through certain group processes that facilitate trust so that information and support can be easily shared amongst members. The role in embedding the behaviour of sharing information and giving support depends in the first instance on the general role modelling behaviour of supervisors (Ellemers, Gilder, and Haslam 2004). Within the nursing context, the importance of good leadership on the quality of teamwork is even more important because it can affect patient outcomes (Firth-Cozens 2001; Thomas, Sexton, and Helmreich 2003). One of the most important factors affecting patient outcomes is the quality of communication between healthcare workers because when the transfer of information is poor, the likelihood of adverse outcomes is increased significantly. Further, nurses operate increasingly in an environment of role ambiguity (Elbright, Urden, Patterson and Chalko 2004). Therefore, a direct relationship between nurses' satisfaction with their supervisor-subordinate relationship and their perceptions of teamwork is expected, as follows:

H1: Public and private sector nurses' satisfaction with their supervisor-subordinate relationships is positively related to their satisfaction with teamwork.

\section{Role ambiguity in relation to patients}

Role clarity refers to a situation where nurses have relevant information and support to be effective in treating the patient. Role ambiguity is the opposite of role clarity and increases the incidence of adverse outcomes for patients (Firth-Cozen 2001). Role clarity is facilitated by an effective supervisor-subordinate relationship and a perception of satisfaction 
with the quality of teamwork. In contrast, role ambiguity is facilitated when nurses receive conflicting or limited messages about what a patient requires (Jolke and Duhan 2000).

The issue of ambiguity in relation to clients (or 'patients' in terms of nurses) has been affected by the implementation of recent reforms in the public sector. In particular these reforms have focused on replacing the public sector management model that relied on the power and professionalism of its professionals (such as nurses and doctors) to ration the distribution of public goods and services within a private sector model focused on achieving outcomes (Ackroyd, Kirkpatrick and Walker 2007; Pollitt and Bouckaert 2000). The changes that occurred were numerous.

One important goal associated with the reforms and often identified by government and public sector managers alike included a movement towards a more client-centred approach. The goal was to change management practices so that public sector employees could deliver quicker decision-making and more flexible responses to meet different clients' demands. However, Kelly (2005) argues that these reforms have been partially implemented at best. Instead, the reforms have led to more bureaucracy with most organisational activities geared towards achieving efficiency and accountability goals, signifying in turn that the goal of becoming more client-centred is at best a secondary focus (Behn 2002; Kelly 2005; Lynn 2001). They argue that the proof is in the activities and processes now undertaken by public sector employees. For example, an important tool needed in becoming client-centred is the introduction of performance indicators to measure client satisfaction levels and Kelly (2005) argues the public sector has been slow to embrace such measures. Hence, some researchers believe that the requirement for public sector employees to understand more than the technical needs and requirements of the client outside the professional technical realm is also less of a priority. 
Public sector nurses experience role ambiguity in relation to their patients when they do not know what the patient needs because they lack information, and/or resources and support (Jolke and Duhan 2000). Role ambiguity is greatest when there is poor communication of expectations, relationships, and responsibilities and it affects nurses in particular because of the nature of their work situated between other allied health professionals and the patient (Dodd-McCue, Tartaglia, Veazey, \& Streetman, 2005). In practice, this means that when nurses experience high quality LMX and teamwork, they are more likely to have access to relevant information, resources and support (Jolke and Duhan 2000; Rhoads, Singh and Goodell 1994). The following hypotheses test this proposition:

H2: Public and private sector nurses' satisfaction with teamwork is positively related to their perceptions of patient role ambiguity.

\section{Employees’ perceptions of wellbeing}

Past research suggests that employees’ perceptions of wellbeing significantly affect their outcomes (Gerstner and Day 1997; Judge and Watanabe 1993). However, there are mixed findings about the relationship between employee's perception of support from supervisors and other colleagues, stressors (such as that caused by role ambiguity) and wellbeing. Some researchers suggest a significant relationship because perception of support acts as a buffer of workplace stressors (Halbesleben and Buckley, 2006). For example, if a nurse is experiencing role ambiguity because they are unsure about how to treat a patient's clinical problem because of an overarching complicated mental disorder, asking advice from those who have experience may immediately elevate their perception of stress. However, other research by Beehr, Farmer, Glazer, Gudanowski and Nair, (2003) argue that the results of such research are inconsistent and in need of further research. One issue could be the definition and measure used to capture wellbeing. 
Wellbeing has multiple definitions, conceptualisations and measurements, and a review of the literature suggests three categories: a) psychological wellbeing (which examines employees' levels of satisfaction with processes and practices in the workplace), b) physical wellbeing (which examines employees' health outcomes, from stress and accidents for example) and c) social wellbeing (which examines the quantity and quality of workplace social networks as well as employees’ perceptions of fairness and equity) (Grant et al. 2007). Diener (2000) defines psychological wellbeing as employees' attitudes and feelings about the work context and this is the definition adopted in this paper. It differs from job satisfaction because it captures a perception of more than satisfaction with the job to include satisfaction with both tangible and intangible aspects of the work context.

There are many conceptualisations of the first of these categories, psychological wellbeing (See Cooper and Cartwright 1994; Daniels and Guppy 1994, 1997). Psychological wellbeing has been measured by Burke and Greenglass (2000) using psychosomatic symptoms (for example, headaches), while Parasuraman, Greenhaus and Granrose (1992) measured wellbeing based on job satisfaction and life stress. In contrast, Warr $(1987 ; 1990)$ uses the term 'affective wellbeing' as a component of mental health (the other components of health are ‘competence’, ‘autonomy’, ‘aspiration’ and ‘integrated functioning') while Danna and Griffin (1999) conceptualised ‘health’ as a sub-component of ‘wellbeing’ because the latter is considered to be broader and more encompassing than the former. Their wellbeing framework comprises the combination of mental, psychological, physical and physiological indicators, plus general physical health. However, these previous measures are considered limited. In particular, Grant et al (2007) argues that previous conceptualisations failed to capture a complete gamut of components comprising psychological wellbeing and that it comprises two components: a) the hedonic section (which focuses on employees’ perceptions of pleasure invoking either negative or positive thoughts or feelings - usually measured by 
employees' levels of job satisfaction); and b) the eudaimonic section (which refers to employees' perceptions of whether they have reached their potential - measured by employees' feelings of fulfilment in reaching their goals).

Further, van der Doef and Maes (1999) criticised previous measures because they focused on job characteristics, largely ignoring the impact of the job situation itself. They argue for "more occupation-specific measurements for specific occupational groups" (van der Doef and Maes 1999: 110). Hence, whilst there is previous research suggesting a tentative link between perception of support, work stressors and psychological wellbeing, it is unclear whether there is a relationship between a potential cause of work stress, namely role ambiguity and psychological wellbeing. Further, no research has measured similarities and differences across the public and private sectors. This information is tested guided by the following hypotheses:

H3: There is a positive relationship between public and private sector nurses' perceptions of patient role ambiguity and their perceptions of wellbeing.

H4: There is a positive relationship between public and private sector nurses' perceptions of LMX, teamwork and patient role ambiguity and their perceptions of wellbeing.

\section{Public and private sector context}

We live in an aging society that will increasingly make greater demands on healthcare services. Without an adequate supply of nurses, the healthcare system will likely collapse, so nurses' retention is vital. The healthcare sector faces major problems in retaining an aging staff and whilst the importance of supervisor-subordinate relationships is acknowledged as critical to retaining nurses, it is unclear whether the management of nurses is similar across 
public and private sector hospitals. As previously stated, both public and private sector hospitals have similar acute clinical settings and experience comparable patient case mix, because of public-private partnerships and contracting out of beds (Brown and Barnett 2004). However, the values informing management practices in the public sector may be different to the private sector, as argued by Steane (1997), because public sector reforms may have negatively impacted upon public sector supervision practices. According to Currie and Procter (2002), public sector managers, such as nurse unit managers (NUMs), have more managerial power compared with their private sector counterparts. Additionally, Hoque, Davis and Humphries (2004) challenge whether the changes have delivered a more effective form of supervision in the public sector. They argue that public sector managers such as NUMs have been ill-equipped in terms of resourcing or management up-skilling to motivate their subordinates to deliver greater effectiveness (Hoque, et al. 2004). A recent study by Hardie and Critchley (2008) suggests that the Australian public perceive that private sector hospitals deliver a higher quality of care, suggesting a better managed context. To examine this premise, the following hypothesis is proposed:

H5: Private sector nurses have significantly higher levels of satisfaction with their supervisor-subordinate relationships and teamwork, lower perceptions of patient role ambiguity and in turn, higher perceptions of wellbeing.

\section{METHODS}

This research uses a cross-sectional design to gather data to test whether the quality of supervisor-subordinate relationships and teamwork affect the levels of nurses' role ambiguity in relation to patients and wellbeing for. Data were collected during 2008 using a surveybased, self-report strategy (Ghauri and Gronhaug 2002). The emerging patterns of data were then compared with the findings of previous research. 
The samples included public and private sector nurses from four states across Australia, working in either public or private small ( $<300$ beds), medium (300-500 beds) or large ( $>500$ beds) hospitals, and in both rural and urban locations. The 3 public hospitals comprised 1 large, medium and small hospital, while the 7 private hospitals comprised 4 small, 2 medium and 2 large (see Table 1). Healthcare is provided in both public and private hospitals in Australia. Approximately 60\% percent of hospital beds are provided by the public sector and $40 \%$ are provided by the private and non-profit sectors (Gee, 2007). However, in Australia, public patients are serviced in private sector hospitals and vice versa because of public-private partnerships (Brown and Barnett, 2004). As a result, the type of clinical work undertaken and the patient case mix is similar across both public and private hospitals (Brown and Barnett, 2004).To gather data from nurses, 4,800 anonymous surveys were distributed to the 10 hospitals and nurses were invited to participate. The response was 1138 useable surveys - a response rate of approximately 24\%. (The response rate for the public sector was $29.6 \%$ and for the private sector was $22.5 \%$.)

[Table 1 inserted here]

Path analysis was used to test the relationship between supervision practices and firstly, nurses' perceptions of teamwork and role ambiguity and in turn, wellbeing. In particular, path analysis using an ordinary least squares (OLS) approach was used to test the hypotheses. The advantage of path analysis is that it permits more than one equation to predict the dependent variable (i.e. wellbeing) and therefore it includes the indirect association with wellbeing into the bigger equation. OLS is an explanation of variance and the overall $\mathrm{R}^{2}$ measure identifies the 'goodness of fit' overall for the proposed model (Ahn 2002). Another advantage of using path analysis with an OLS approach is that it estimates parameters within an independent system, which could avoid the problem of multicollinearity (Grapentine 2000). For this reason, OLS was used for analysis of the data. 


\section{Measures}

The measures were generated from the extant literature and presented using statements to be rated on a 6-point Likert-type scale, with $1=$ strongly disagree, ranging to $6=$ strongly agree. Appendix 1 details the items used in the survey. Satisfaction of nurses with the quality of their supervisor-subordinate relationship was measured using a seven-item unidimensional scale (LMX-7), developed by Graen and Uhl-Bien (1995). According to Gerstner and Day (1997), the uni-dimensional scale updated by Graen and Uhl-Bien (1995) is the most commonly used tool for measuring LMX quality and has the best psychometric properties of all the instruments reviewed. Nurses' satisfaction with Teamwork was measured using Rubin, Palmgreen and Sypher's (1994) version of an organisational culture survey developed by Glaser, Zamanou and Hacker (1987), using employees’ level of satisfaction as a function of teamwork, morale, information flow, involvement and supervision. Role ambiguity in relation to patients was measured using 3 items of Johlke and Duhan's (2000) instrument and was reverse scored; a higher score reflects role clarity, whereas a lower score represents role ambiguity. Perception of wellbeing was operationalised using an instrument developed by Brunetto, Far-Wharton and Shacklock (2011 forthcoming) to address criticisms raised by van der Doef and Maes (1999) that more occupation-specific measurements are needed. This measure of psychological wellbeing is specifically suited to nursing and is operationalised as a function of the hedonic part (focusing on nurses' perceptions of pleasure invoking either negative or positive thoughts or feelings) in addition to the eudaimonic part (focusing on nurses’ perceptions of fulfillment in achieving their goals) (Grant, et al. 2007).

\section{RESULTS}


The public sector nurse sample comprised $38 \%$ males and $62.5 \%$ females and the private sector nurse sample comprised $3.7 \%$ males and $96.2 \%$ females, with the combined samples being $10.8 \%$ male and $89.2 \%$ female (see Table 2 ). Within the public sector nursing sample, 52 were Nurse Unit Managers (NUM), 60 were senior clinical nurses, 101 were Registered Nurses (RN), and 18 were Enrolled Nurses (EN) and 7 were Assistants in Nursing (AIS). Within the private sector nursing sample, 55 were Nurse Unit Managers (NUM), 112 were senior clinical nurses, 626 were Registered Nurses (RN), and 103 were Enrolled Nurses (EN) and 4 were Assistants in Nursing (AIS). Further, 50\% were aged over 45 years. The sample is therefore representative of the Australian nursing demographic, where about 9\% are males, $40 \%$ are aged 45 years or older, and nearly $90 \%$ are qualified nursing professionals (ABS 2005).

\section{[Insert Table 2 here]}

\section{Confirmatory Factor Analysis}

Each variable has been developed and validated in previous research; hence the findings detailed here are the results of a confirmatory factor analysis. The correlation matrix identified many correlations exceeding .3, indicating the matrix was suitable for factoring. The Bartlett's test for Sphericity was significant (Chi-square value=10,587.605, $\mathrm{p}<.001$. df 177) and the Kaiser-Meyer-Olkin (KMO) measure of sampling adequacy was .895 - well above the .6 requirement. When Principal Axis Factoring was undertaken to extract the variables, four factors had eigenvalues greater than one and $69.38 \%$ of the variance could be explained using these four factors. Table 3 shows the results of principal axis factoring using a rotated factor matrix.

[Insert Table 3 here] 


\section{Correlation Matrix}

Tables 4 and 5 details the correlation coefficients for each variable. Table 4 provides the correlations for the overall nursing sample, while Table 5 breaks up the private sector sample (with results provided under the diagonal line) and the private sector results provided above the diagonal). All variables were significantly related to one another except for the control variable - location of the employing hospital.

[Insert Tables 4 and 5 here]

\section{Results from analysis}

To address the first hypothesis (Public and private sector nurses' satisfaction with their supervisor-subordinate relationships is positively related to their satisfaction with teamwork), a regression analysis was undertaken and the findings suggest that the hypothesis is supported (see Table 6). The findings indicate that

(a) Public sector nurses' satisfaction with their supervisor-nurse relationship accounted for $13.6 \%$ of the variance in their satisfaction with teamwork. The mean for satisfaction with supervisor-nurse relationships (4.53 of 6) suggests that public nurses are at least slightly satisfied, while the mean for teamwork (4.1 of 6) suggests that public nurses were just slightly satisfied with teamwork.

(b) Private sector nurses' satisfaction with their supervisor-nurse relationships accounted for $17.1 \%$ of the variance in their satisfaction with teamwork. The mean for their satisfaction with supervisor-nurse relationships (4.7), suggests that private nurses are more than slightly satisfied, while the mean for teamwork was 4.6, suggesting that private nurses are more than slightly satisfied with teamwork.

The results also indicate that approximately a sixth of the variance of public and private sector nurses' satisfaction with teamwork is accounted for by satisfaction with their supervisor/nurse relationships. Secondly, the findings suggest that the higher the level of 
satisfaction with supervisor-nurse relationships, the higher the level of satisfaction with teamwork.

\section{[Insert Table 6 here]}

To address the second hypothesis (Public and private sector nurses' satisfaction with teamwork is positively related to their perceptions of patient role ambiguity), a regression analysis was undertaken and the findings suggest that the hypothesis is supported (see Table 7). The findings indicate that:

(a) Public sector nurses' perception of teamwork accounts for $4.5 \%$ of the variance in their perceptions of patient role ambiguity. The mean for teamwork (4.1) suggests only slight satisfaction with teamwork, but for role ambiguity (5.05) it suggests nurses perceive role clarity (not role ambiguity) in relation to their patients.

(b) Private sector nurses' perception of teamwork accounts for $1.5 \%$ of the variance in their patient role ambiguity. The means for teamwork (4.6) and role ambiguity (5.6) also suggests slight satisfaction with teamwork plus role clarity in relation to their patients.

This means that less than 5 percent of the variance of both public and private sector nurses' perceptions of role ambiguity can be accounted for by their satisfaction with teamwork. Whilst the correlation is significant, the findings suggest that teamwork contributes minimally to nurses’ perceptions of patient role ambiguity. However, the findings also indicate that higher levels of teamwork satisfaction are associated with higher levels of role clarity (low levels of role ambiguity).

\section{[Insert Table 7 here]}

To address the third hypothesis (There is a positive relationship between public and private sector nurses' perceptions of patient role ambiguity and their perceptions of 
wellbeing), a regression analysis was undertaken and the findings suggest that the hypothesis is supported (see Table 8).

(a) Public sector nurses' perceptions of patient role ambiguity accounted for $17.4 \%$ of the variance in their perceptions of wellbeing. The mean for nurses' perception of role ambiguity (5.05) indicates role clarity, while the mean for wellbeing (4.34) suggests public nurses are at least slightly satisfied with their wellbeing.

(b) Private sector nurses' perceptions of patient role ambiguity accounted for $8.5 \%$ of the variance in their wellbeing. The mean for nurses’ perceptions of role ambiguity (5.6) suggests role clarity and the mean for wellbeing (4.72) suggests private nurses are close to being satisfied with their wellbeing levels.

This means that the role ambiguity experienced by public sector nurses accounts for more than double the variance in private sector nurses' perceptions of wellbeing. Secondly, the findings indicate that the greater the patient role clarity, the greater the perception of wellbeing.

\section{[Insert Table 8 here]}

To address the fourth hypothesis (There is a positive relationship between public and private sector nurses' perceptions of LMX, teamwork and patient role ambiguity and their perceptions of wellbeing), a regression analysis was undertaken and the findings suggest that the hypothesis is accepted. Age and gender were included in this regression because of the potential significant relationship and age was found to be significant (See Table 9).

(a) Public sector nurses' perceptions of LMX, teamwork and patient role ambiguity (including demographics - age and gender) accounted for $37.7 \%$ of the variance in their perceptions of wellbeing. 
(b) Private sector nurses' perceptions of LMX, teamwork and patient role ambiguity (including demographics - age and gender) accounted for $23.6 \%$ of the variance in their wellbeing.

This means that these three factors account for over a third of the variance in public sector nurses’ perceptions of wellbeing and more than a fifth of private sector nurses' perceptions of wellbeing. However, it is likely that age differences accounted for some of this variance.

\section{[Insert Table 9 here]}

To address the fifth hypothesis (Private sector nurses have significantly higher levels of satisfaction with their supervisor-subordinate relationships and teamwork, lower perceptions of patient role ambiguity and in turn, higher perceptions of wellbeing), an independent t-test was undertaken (see Table 10). The significantly different means suggest that the management experiences in public hospitals are significantly different to that of private hospitals and hence the hypothesis is supported. With higher means for all four factors, it suggests that private sector nurses are more satisfied with all four factors (where higher means for role ambiguity actually means better role clarity). Additionally, the findings indicate a significantly different gender and age mix in the private sample compared with the public sample.

[Insert Table 10 here]

\section{DISCUSSION}

This paper used a LMX theoretical lens to examine the association between supervisor-nurse relationships and nurse outcomes, such as nurses’ perceptions of teamwork, and in turn patient role ambiguity and finally, wellbeing. Under ideal conditions, LMX theory argues that high quality supervisor-subordinate relationships facilitate the sharing of knowledge, support and resources in turn, enabling high quality teamwork (Gerstner and Day 
1997; Mueller and Lee 2002; Podsakoff, et al 2000; Wayne, Shore and Linden 1997; Yrie, Hartman and Galle 2003). Such ideal work environments promote problem-solving and consequently reduce the level of role ambiguity experienced by nurses in relation to patients while simultaneously enhancing nurses' perceptions of wellbeing. The findings from this study suggest nurses are at least slightly satisfied with their supervisor-nurse relationships, the quality of teamwork and their sense of wellbeing. They also appear to experience role clarity rather than ambiguity in relation to the patients. Additionally, the results suggest that supervisor-nurse relationships, teamwork and role ambiguity explains over a third of the variance of wellbeing for public sector nurses and over a fifth for private sector nurses. However, because both age and gender were significant, it suggests that some of the variance of wellbeing can be explained by age in particular (See Figure 1).

The second theme of the paper was to examine the extent to which private and public sector nurses experienced similar or different perceptions of supervisor-nurse relationships, teamwork, patient role ambiguity, and wellbeing. Past research produced contradictory evidence, with some authors suggesting that public nurses experience similar management practices and outcomes (Brown and Barnett 2004), whereas Steane (1997) argues that the differences in the core values of hospitals across public and private/non profit hospitals probably produced differences in management practices. The findings from this research strongly supports Steane's (1997) work by identifying significant differences between the public and private sector nurses' perceptions of the quality of nurse supervision practices, teamwork, role ambiguity and wellbeing. The findings suggest that private sector nurses are significantly more satisfied compared with public sector nurses. However, other factors may further explain the differences between public and private sector nurses' behaviour. For example, the individual nurse workload, the particular management structure, the 
composition and size of teams, and even perceptions of job autonomy. Further research into these possibilities would be worthwhile.

This study has a number of limitations. The main limitation is the use of self-report surveys causing common methods bias. However, Spector (1994) argues that self-reporting methods is legitimate for gathering data about employees’ perceptions, as long the instrument reflects an extensive literature review and pattern-matching is used to support interpretations of the data. Following this, the use of only one side of the supervisor-subordinate relationship (the nurses) to report the quality of that relationship creates a limitation to the research. If asked, supervisors may have reported differently on the relationship and its association with the variables being measured. Further, the response rate of $24 \%$ is marginally low. One explanation could be that nurses feared retribution from management (if their opinions or comments about their supervisors were disclosed in any way), which reduced their willingness to participate. A further limitation relates to the generalisability of the findings. While the overall sample is representative of nurses in Australia, the higher proportion of males and fewer females in the public sector sample is not representative. Therefore, the findings are not necessarily generalisable across Australia's public health sector nurses. Finally, the much greater number of nurses in the private sector sample would have slanted the findings towards their perceptions and opinions, as opposed to those from the public sector.

\section{Implications}

Of the two groups, private sector nurses were the most satisfied with their supervisornurse relationship and teamwork, and have higher perceived levels of role clarity (instead of role ambiguity) and wellbeing. However, the means for both groups suggest that both public 
and private sector nurses appear to operate in work contexts that are frustrating for them and that these organisational conditions are unlikely to improve their perceptions of wellbeing. Wellbeing is becoming an increasingly important measure of HRM outcomes (Gerstner and Day 1997; Judge and Watanabe 1993) and public sector employees appear less satisfied with each workplace measure and outcomes compared with private sector employees. Therefore, it seems likely that the current management reform practices creating the present supervisornurse relationships may require change. The HRM implications from this include those for development and training (for example, leadership training for current supervisors, plus mentoring and coaching from valued older nurses), targetted future selection of appropriate supervisors, as well as setting supervisor performance goals that ensure the effective management of nurses. Public sector reforms aimed at increasing the power of supervisors and reducing the power of professionals may be delivering efficiency gains for the government and public sector organizations, however, the outcomes may not as beneficial for enhancing the quality of supervisor-nurse relationships.

\section{CONCLUSION}

The findings from this study add new knowledge about the association between effective workplace relationships and nurse outcomes. Previous research has identified that effective workplace relationships enhance retention (Cohen 2006; Cropanzano and Mitchell 2005; Hodson 2004; Masterson et al 2000; Tauton, et al 1997), predict nurses' job satisfaction and organisational commitment (Brunetto, Farr-Wharton and Shacklock 2010; 2011) and wellbeing (Rodwell et al 2009), especially for women (Shacklock, Brunetto and Nelson 2009) and that relationships are significant to the loyalty and thus retention of older nurses (Moseley et al 2008). The findings from this study identify that supervisor-nurse relationships affect nurses’ perceptions of teamwork, patient role ambiguity and wellbeing. 
Further, the relationship is different for public sector nurses compared with private sector nurses.

Additionally, this research provides new information about the factors affecting wellbeing. Previous research measured psychological wellbeing using a variety of factors, but these earlier studies were criticised as not being sufficiently occupation specific. This study provides new information that between a fifth and a third of the variance of private and public sector nurses' wellbeing can be explained by their satisfaction with supervisor-nurse relationship, teamwork and patient role ambiguity, although demographic factors (age and gender) also contributed.

As a result, healthcare organisations and HRM are now better equipped to develop successful strategies to attract, manage and retain valued nurses. Clearly, the role of supervisor is key to these nursing HRM strategies, and supervisors should therefore be selected, trained and managed to ensure high quality relationships can develop and be maintained with each of their nurses.

To conclude, future research could broaden the range of nurses studied to include those employed in non-hospital settings, such as aged care and community nursing. Also, more research is required about how the quality of supervisor-subordinate relationships affects outcomes of other types of professionals found in both the public and private sector. Further, comparative studies are required to examine the impact of these factors in different countries - especially those countries experiencing a shortage of nurses similarly to Australia. 


\section{Reference}

Ackroyd, S., I. Kirkpatrick, and R. Walker. 2007. Public management reform in the UK and its consequences for professional organization: A comparative analysis. Public Administration 85 (1):9-26.

Adcroft, A., and R. Willis. 2005. The (un)intended outcome of public sector performance measurement. The International Journal of Public Sector Management 18 (4/5):386400.

Ahn, J. 2002. Beyond single equation regression analysis: Path analysis and multi-stage regression analysis. American Journal of Pharmaceutical Education 66:37-42.

Australian Bureau of Statistics. 2005. Year Book Australia: Labour force participation in Australia, Catalogue 6105.0. Canberra: Australian Bureau of Statistics. . 2009. Retirement and retirement intentions, Australia. Canberra: Australian Bureau of Statistics.

Avis, J. 1996. The enemy within: Quality and managerialism in education. In Knowledge and Nationhood, edited by J. Avis, M. Bloomer, G. Esland, D. Gleeson and P. Hodkinson. London Cassell, 105-120.

Beehr, T, Farmer, S., Glazer, S., Gudanowski, D, \& Nair, V 2003 The enigma of social support and occupationalstress: Source congruence and gender role effects. Journal of Occupational Health Psychology, 8, 220-231.

Behn, R. 2002. The psychological barriers to performance management or why isn't everyone jumping on the performance management bandwagon? Public Performance and Management Review 26 (1):5-25.

Bell, N. S., and M. Narz. 2007. Meeting the challenges of age diversity in the workplace. The CPA Journal 77 (2):56-59.

Bindi, K., C. Clegg, M. Patterson, A. Robertson, C. Stride, T. Wall, and S. Woods. 2008. The impact of human resource management practices on company productivity: A longitudinal study. Personnel Psychology 61:467-501.

Bolton, S. 2003. Multiple roles? Nurses as managers in the NHS. International Journal of Public Sector Management 16 (2):122-130.

Brown, L., and J. Barnett. 2004. Is the corporate transformation of hospitals creating a new hybrid healthcare space? Social Science Medicine 58 (427-44).

Brunetto, Y., and R. Farr-Wharton. 2005. The impact of NPM on the job satisfaction of Australian public sector employees. Asian Pacific Journal of Human Resources 41:289-304.

2007. Comparing the impact of management practices on public sector nurses' and administrative employees' commitment to the organisation. Asian Pacific Journal of Health Management 2 (1):17-34.

Brunetto, Y., R. Farr-Wharton, and K H. Shacklock. 2010. The impact of supervisorsubordinate relationships on morale: implications for public and private sector nurses' commitment. Human Resource Management Journal 20 (2):206-225.

— 2011 forthcoming. Using the Harvard HRM model to conceptualise the impact of changes to supervision upon HRM outcomes for different types of public sector employees. International Journal of Human Resource Management.

Brunetto, Y., and Rod Farr-Wharton. 2006. The importance of effective organisational relationships for nurses: A social capital perspective. International Journal of Human Resources and Development 6 (2/3/4):232-247.

Buchan, J., and L. Calman. 2004. The global shortage of registered nurses: An overview of issues and Actions. Geneva: International Council of Nurses. 
Buchanan, J., and G. Considine. 2002. "Stop telling us to cope" NSW nurses explain why they are leaving the profession. A Report for the NSW Nurses Association Sydney: Australian Centre for Industrial Relations Research and Training, University of Sydney.

Burke, R. J., and E. R. Greenglass. 2000. Hospital restructuring and nursing staff well being: the role of coping. International Journal of Stress Management 7 (1):49-59.

Butterfield, R, C Edwards, and J Woodall. 2005. The new public management and managerial roles: The case of the police sergeant. British Journal of Management 16:219-341.

Cohen, Jayne. 2006. The aging nursing workforce: How to retain experienced nurses Journal of Healthcare Management 51 (4):233- 246.

Cooper, C. L., and S. Cartwright. 1994. Healthy mind; healthy organisation - a proactive approach to occupational stress. Human Relations 47 (4):455-472.

Cropanzano, R., and M. Mitchell. 2005. Social exchange theory. Journal of Management 31:874-900.

Currie, G, and S Procter. 2002. The interaction of human resource policies and practices with the implementation of teamworking: Evidence from the UK public sector. The International Journal of Human Resource Management 14 (4):581-599.

Daniels, K., P. Brough, A. Guppy, K. M. Peters-Bean, and L. Weatherstone. 1997. A note on a modification to Warr's measures of effective well being at work. Journal of Workplace and Organizational Psychology 70:129-138.

Daniels, K., and A. Guppy. 1997. Stressors, locus of control, and social support as consequences of affective psychological well being. Journal of Occupational Health Psychology 2 (2):156-174.

Danna, Karen, and Ricky W. Griffin. 1999. Health and well-being in the workplace: A review and synthesis of the literature. Journal of Management 25 (3):357-384.

Dawson, J., M. West, and X. Yan. 2008. Positive and negative effects of team working in healthcare: 'Real' and 'pseudo' teams and their impact on healthcare safety. Working Paper, Aston University, Birmingham, UK.

Elbright, P., L. Urden, E. Patterson, and B. Chalko. 2004. Themes surrounding novice nurses' near-miss and adverse event situations. Journal of Nursing Administration 34 (11):531-38.

Ellemers, N., D. D. Gilder, and A. S. Haslam. 2004. Motivating individuals and groups as work: a social identity perspective on leadership and group performance. Academy of Management Review 29 (3):459-78.

Firth-Cozens, J. 2001. Teams, Culture and Managing Risk. In Clinical Risk Management: enhancing patient safety, edited by C. Vincent 2nd ed. 355-368.

Gee, C., 2007. The Contribution of the Australian Private Sector Hospitals Sector. Asian Pacific Journal of Health Management 2 (1): 41-46.

Gerstner, C., and D. Day. 1997. Meta-analytic review of leader-member exchange theory: Correlates and construct issues. Journal of Applied Psychology 82:827-844.

Ghauri, P , and K. Grønhaug. 2002. Research methods in business studies: A practical guide. 2nd ed. Harlow, UK: Financial Times Prentice Hall.

Glaser, S., S. Zamanou, and K. Hacker. 1987. Measuring and interpreting organisational culture. Management Communication Quarterly 1 (2):173-198.

Graen, G., and M. Uhl-Bien. 1995. Relationship-based approach to leadership: Development of leader-member exchange (LMX) theory of theory over 25 years: Applying a multilevel multi-domain perspective. Leadership Quarterly 6 (2):219-247. 
Grant, A. M., M. K. Christianson, and R. H. Price. 2007. Happiness, health, or relationships? Managerial practices and employee well-being tradeoffs. Academy of Management Perspectives 21 (3):51-63.

Grapentine, T. 2000. Path analysis vs. structural equation modeling. Marketing Research, 12 (3):13-20.

Halbesleben, J.R.B., and M.R. Buckley, 2006. Social comparison and burnout: The role of relative burnout and received social support. Anxiety, Stress \& Coping: An International Journal, 19:259-278.

Hoggett, P 1994. The politics of the modernisation of the UK welfare state. In Towards a Post-Fordist Welfare State?, edited by R. Burrows and G. Holmes. London: Routledge.

Hoque, K., S Davis, and M Humphries. 2004. Freedom to do what you are told: Senior management's autonomy in an NHS Acute Trust. Public Administration 82 (2):355376.

Johlke, Mark C., and Dale F. Duhan. 2000. Supervisor communication practices and service employee job outcomes. Journal of Service Research 3 (2):154-165.

Judge, T., and S. Watanabe. 1993. Another look at the job satisfaction-life satisfaction relationship. Journal of Applied Psychology 78 (6):939-948.

Katzenbach, J., and D. Smith. 1993. The wisdom of teams: Creating the high-performing organisation. Boston: Harvard School Press.

Kelly, J. 2005. The dilemma of the unsatisfied customer in a market model of public administration. Public Administration Review 65 (1):76-84.

Lynn, L (Jr). 2001. The myth of the bureaucratic paradigm: What traditional public administration really stood for Public Administration Review 61 (2):144-159.

Masterson, S., K. Lewis, B. Goldman, and S. Taylor. 2000. Integrating justice and social exchange: The differing effects of fair procedures and treatment on work relationships. Academy of Management Journal, 41: 738-48.

Moseley, Amanda, Lesley Jeffers, and Jan Paterson. 2008. The retention of the older nursing workforce: A literature review exploring factors that influence the retention and turnover of older nurses. Contemporary Nurse 30 (1):46-56.

Mueller, B., and J. Lee. 2002. Leader-member exchange and organizational communication satisfaction in multiple contexts. Journal of Business Communication 39 (2):220-244.

Newman, K., U. Maylor, and B. Chansarkar. 2002. The nurse satisfaction. Service quality and nurse retention chain: Implications for management of recruitment and retention. Journal of Management in Medicine 16 (4/5):271-292.

Parasuraman, S., Greenhaus, J. H. 1992. Role stressors, social support, and well being among two career couples. Journal of Organisational Behaviour 13 (4):339-356.

Podsakoff, P M, S. B MacKenzie, J. B. Paine, and D. G. Bachrach. 2000. Organizational citizenship behaviors: A critical review of the theoretical and empirical literature and suggestions for future research. Journal of Management 26 (3):513-563.

Productivity Commission. 2005. Australia's Health Workforce. Canberra: Productivity Commission, Commonwealth of Australia.

Rhoads, Gary K., Jagdip Singh, and Phillip W. Goodell. 1994. The multiple dimensions of role ambiguity and their impact upon psychological and behavioural outcomes of industrial salespeople. Journal of Personal Selling and Sales Management 14:1-22.

Rodwell, J., A. Noblet, D Demir, and P. Steane. 2009. Supervisors are central to work characteristics affecting nurse outcomes. Journal of Nursing Scholarship 41 (3):310320.

Rubin, R., P Palmgreen, and H Sypher. 1994. Communication research measures: A sourcebook. New York: Guildford Press. 
Secombe, I., and G Smith. 1997. Taking part: Registered nurses and the labour market in 1997. Grantham, England: Grantham Book Services.

Shacklock, K.H., Y. Brunetto, and S. Nelson. 2009. The different variables that affect older males' and females' intentions to continue working. Asia Pacific Journal of Human Resources 47 (1):79-101.

Smith, K., Kaminstein, D. S., Makadok, R. J. 1995. The health of the corporate body: Illness and organizational dynamics. Journal of Applied Behavioural Science 31:328-351.

Spector, P. E. 1994. Using self-reported questionnaires in OB research: A comment on the use of a controversial method. Journal of Organisational Behavior 15 (5):385-392.

Steane, P. 1997. Oils Ain’t Oils! Strategy Across Sectors. International Journal of Public Sector Management 10:461-470.

Tauton, R.L., D.K. Boyle, C.Q. Woods, H.E. Hansen, and M.J. Bott. 1997. Manager leadership and retention of hospital staff nurses. Western Journal of Nursing Research 19 (2):205-226.

Thomas, E., B Sexton, and R Helmrich. 2003. Discrepant attitudes about teamwork among critical care nurses and physicians. Critical Care Medicine 31 (3):956-959.

Van der Doef, M., and S. Maes. 1999. The job demand-control-support model and psychological well-being: A review of 20 years of empirical research. Work \& Stress 13 (2):87-114.

Warr, P. 1987. Work, unemployment, and mental health. Oxford: Clarendon Press.

- 1990. The measurement of well being and other aspects of mental health. Journal of Occupational Psychology 63:193-210.

Wayne, S., L. Shore, and R. Linden. 1997. Perceived organisational support and leader exchange: A social exchange perspective. Academy of Management Journal 40 (1):82-111.

Yrie, A., S. Hartman, and W. Galle. 2003. Examining communication style and leadermember exchange: considerations and concerns for managers. International Journal of Management 20 (1):92-100. 


\section{TABLES}

Table 1: Details about hospitals from which nurses were surveyed

\begin{tabular}{llllll}
\hline & Urban/ & $\begin{array}{l}\text { Dealing } \\
\text { with } \\
\text { Acute } \\
\text { cases }\end{array}$ & Teaching & $\begin{array}{l}\text { Size: Classed as } \\
\text { Large: }>500 \text { beds } \\
\text { Medium: } 300-500 \text { beds } \\
\text { Small: }<300 \text { beds }\end{array}$ \\
\hline Public Hospital 1 & Urban & Yes & Yes & Large & (760 beds) \\
Public Hospital 2 & Regional & Yes & No & Small & (160 beds) \\
Private Hospital 1 & Urban & Yes & Yes & Large & (578 beds) \\
Private Hospital 2 & Urban & Yes & No & Medium (416 beds) \\
Private Hospital 3 & Urban & Yes & No & Medium (317 beds) \\
Private Hospital 4 & Regional & Yes & No & Small & (260 beds) \\
Private Hospital 5 & Urban & Yes & No & Small & (239 beds) \\
Private Hospital 6 & Urban & Yes & No & Small & (219 beds) \\
Private Hospital 7 & Regional & Yes & No & Small & (206 beds) \\
\hline
\end{tabular}

Table 2: Demographics of the samples

\begin{tabular}{lccc}
\hline & $\begin{array}{c}\text { Private sector nurses } \\
(\mathbf{N}=\mathbf{9 0 1})\end{array}$ & $\begin{array}{c}\text { Public sector nurses } \\
(\mathbf{N}=\mathbf{2 3 7 )}\end{array}$ & $\begin{array}{c}\text { TOTAL } \\
\mathbf{( N ~ 1 1 3 8 )}\end{array}$ \\
\hline GENDER: Male & $33(3.7 \%)$ & $90(38 \%)$ & $123(10.8 \%)$ \\
Female & $867(96.2 \%)$ & $148(62.5 \%)$ & $1015(89.2 \%)$ \\
AGE: $<$ 30 years & $74(8.2 \%)$ & $41(17.3 \%)$ & $115(10.1 \%)$ \\
$\mathbf{3 0}$ - 45 years & $340(37.7 \%)$ & $113(47.7 \%)$ & $453(39.8 \%)$ \\
$>$ 45 years & $487(54.1 \%)$ & $83(35 \%)$ & $570(50.1 \%)$ \\
\hline
\end{tabular}

Table 3: Results of Rotated Factor Matrix (Principal axis factoring)

\begin{tabular}{|l|l|l|l|l|}
\hline & Factor 1 & Factor 2 & Factor 3 & Factor4 \\
\hline
\end{tabular}




\begin{tabular}{|c|c|c|c|c|}
\hline Q32 & .710 & & & \\
\hline Q33 & .789 & & & \\
\hline Q34 & .754 & & & \\
\hline Q35 & .797 & & & \\
\hline Q36 & .833 & & & \\
\hline Q26 & & & & .714 \\
\hline Q27 & & & & .927 \\
\hline Q28 & & & & .754 \\
\hline Q78 & & .734 & & \\
\hline Q79 & & .835 & & \\
\hline Q80 & & .768 & & \\
\hline Q81 & & .724 & & \\
\hline Q82 & & .71 & & \\
\hline Q119 & & & .724 & \\
\hline Q120 & & & .804 & \\
\hline Q121 & & & .785 & \\
\hline Q122 & & & .559 & \\
\hline
\end{tabular}

Table 4: Correlations and Cronbach's alpha coefficients -Overall sample

\begin{tabular}{lllllllll}
\hline & & 1 & 2 & 3 & 4 & 5 & 6 & 7 \\
\hline 1 & Location & 1 & & & & & & \\
2 & LMX & -.02 & 1 & & & & & $(.93)$ \\
3 & Teamwork & .01 & $.408^{* *}$ & 1 & & & & $(.857)$ \\
4 & Role Ambiguity & -.05 & $.312^{* *}$ & $.20^{* *}$ & 1 & & & \\
5 & Wellbeing & -.01 & $.4^{* *}$ & $.41^{* *}$ & $.29 * *$ & 1 & & $(.805)$ \\
6 & Gender & -.04 & $.2 * *$ & $.087^{* *}$ & $.5 * *$ & .035 & 1 & \\
7 & Age & -01 & .02 & $.14^{* *}$ & $.14^{* *}$ & $.18^{*}$ & $.066^{*}$ & 1 \\
\hline
\end{tabular}
$\mathrm{N}=1138$.

Statistically significant Pearson correlation scores $-*^{* *} \mathrm{p}<.01, * \mathrm{p}<.05$, Two-tailed tests Cronbach alpha coefficients of the composite scales scores are in brackets 
Table 5: Correlations and Cronbach's alpha coefficients for public and private sector nurses\#

\begin{tabular}{|c|c|c|c|c|c|c|c|c|}
\hline & & 1 & 2 & 3 & 4 & 5 & 6 & 7 \\
\hline 1 & Location & 1 & .07 & -.09 & -.012 & -.045 & -.07 & -.06 \\
\hline 2 & LMX & -.02 & 1 & $.37 * *$ & $.5 * *$ & $.5 * *$ & .01 & .17 \\
\hline 3 & Teamwork & .04 & $.41 * *$ & 1 & $.21^{* *}$ & $.35 * *$ & .14 & -.01 \\
\hline 4 & Role Ambiguity & .003 & $.26 * *$ & $.2 * *$ & 1 & $.42 * *$ & -.039 & .14 \\
\hline 5 & Wellbeing & .035 & $.38 * *$ & $.39 * *$ & $.21^{* *}$ & 1 & .046 & .11 \\
\hline 6 & Gender & .025 & .01 & .03 & .06 & .001 & 1 & -.12 \\
\hline 7 & Age & .023 & .032 & $.1^{* *}$ & $.09 * *$ & $.17^{*}$ & $.056^{*}$ & 1 \\
\hline
\end{tabular}

Table 6: Regression analysis detailing supervisor-nurse relationship as a predictor of satisfaction with teamwork

\begin{tabular}{lccc}
\hline $\begin{array}{l}\text { Satisfaction } \\
\text { with teamwork }\end{array}$ & $\begin{array}{c}\text { Private sector nurses } \\
\beta\end{array}$ & $\begin{array}{c}\text { Public sector nurses } \\
\beta\end{array}$ & $\begin{array}{c}\text { Combined nurses } \\
\beta\end{array}$ \\
\hline LMX & $.414^{* *}$ & $.47^{* *}$ & $.408^{* *}$ \\
F & $185.627^{* *}$ & $66.423^{* *}$ & $212.307^{* *}$ \\
$\mathbf{R}^{2}$ & $\mathbf{1 7 . 1 \%}$ & $\mathbf{1 3 . 6 \%}$ & $\mathbf{1 6 . 7 \%}$ \\
** Correlation is significant at the 0.01 level (2-tailed). &
\end{tabular}

Table 7: Regression analysis detailing satisfaction with teamwork as a predictor of patient role ambiguity

\begin{tabular}{lccc}
\hline $\begin{array}{l}\text { Patient role } \\
\text { ambiguity }\end{array}$ & $\begin{array}{c}\text { Private sector nurses } \\
\beta\end{array}$ & $\begin{array}{c}\text { Public sector nurses } \\
\beta\end{array}$ & $\begin{array}{c}\text { Combined nurses } \\
\beta\end{array}$ \\
\hline Teamwork & $.121^{* *}$ & $.212^{* *}$ & $.203^{* *}$ \\
$\mathrm{~F}$ & $13.367^{* *}$ & $17.596^{* *}$ & $45.845^{* *}$ \\
$\mathbf{R}^{2}$ & $\mathbf{1 . 5 \%}$ & $\mathbf{4 . 5 \%}$ & $\mathbf{4 . 1 \%}$ \\
** Correlation is significant at the 0.01 level (2-tailed). & &
\end{tabular}


Table 8: Regression analysis detailing patient role ambiguity as a predictor of perception of wellbeing

\begin{tabular}{lccc}
\hline $\begin{array}{l}\text { Perception of } \\
\text { wellbeing }\end{array}$ & $\begin{array}{c}\text { Private sector nurses } \\
\beta\end{array}$ & $\begin{array}{c}\text { Public sector nurses } \\
\beta\end{array}$ & $\begin{array}{c}\text { Combined nurses } \\
\beta\end{array}$ \\
\hline Role ambiguity & $.205^{* *}$ & $.418^{* *}$ & $.41^{* *}$ \\
F & $39.37^{* *}$ & $54.234^{* *}$ & $45.845^{* *}$ \\
$\mathbf{R}^{2}$ & $\mathbf{8 . 5 \%}$ & $\mathbf{1 7 . 4 \%}$ & $\mathbf{1 4 . 1 \%}$ \\
\hline$*$ Correlation is significant at the 0.01 level (2-tailed). &
\end{tabular}

Table 9: Regression analysis detailing supervisor-subordinate relationship as a predictor of patient role ambiguity

\begin{tabular}{|c|c|c|c|}
\hline $\begin{array}{lr}\text { Patient } & \text { role } \\
\text { ambiguity } & \end{array}$ & $\begin{array}{c}\text { Private sector nurses } \\
B\end{array}$ & $\begin{array}{c}\text { Public sector nurses } \\
\beta\end{array}$ & $\begin{array}{c}\text { Combined nurses } \\
B\end{array}$ \\
\hline LMX & $.238 * *$ & $.419 * *$ & $.258 * *$ \\
\hline Teamwork & $.263 * *$ & $.195 * *$ & $.261 * *$ \\
\hline Role Ambiguity & $.102 * *$ & $.16^{* *}$ & $.140 * *$ \\
\hline Gender & -.023 & -.049 & -.018 \\
\hline Age & $.132 * *$ & .025 & $.119 * *$ \\
\hline $\mathrm{F}$ & $55.134 * *$ & $19.009 * *$ & $79.987 * *$ \\
\hline $\mathbf{R}^{2}$ & $23.6 \%$ & $37.7 \%$ & $27.4 \%$ \\
\hline
\end{tabular}

Table 10: Results from Independent Samples Test

\begin{tabular}{|c|c|c|c|c|c|}
\hline & Private & ctor ${ }^{\#}$ & Public & $\operatorname{tor}^{\# \#}$ & \\
\hline & $\operatorname{Mean}^{\mathrm{a}}$ & $\overline{\text { SD }}$ & $\overline{\text { Mean }}$ & $\overline{\text { SD }}$ & T value \\
\hline LMX & 4.72 & 1.1 & 4.53 & 1.1 & $2.048 *$ \\
\hline Teamwork & 4.64 & .78 & 4.14 & .92 & $6.448 * *$ \\
\hline Patient role ambiguity & 5.63 & .54 & 5.05 & .86 & $8.413 * *$ \\
\hline Wellbeing & 4.74 & .77 & 4.34 & .83 & $5.692 * *$ \\
\hline Gender & 1.96 & .18 & 1.87 & .32 & $3.241^{*}$ \\
\hline Age & 2.46 & .64 & 2.12 & .74 & $6.094 * *$ \\
\hline
\end{tabular}


Figure 1: Path Analysis showing the impact of LMX, Teamwork, Role Ambiguity (patients) and demographics (age, gender) on Wellbeing

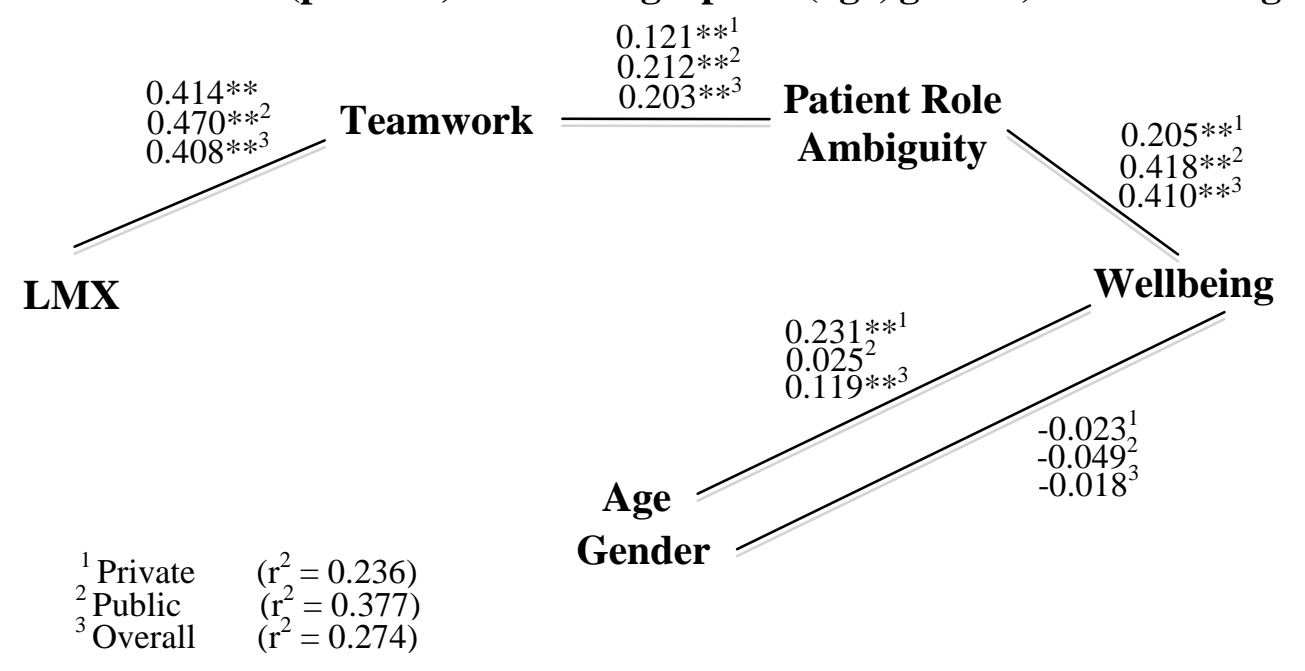




\section{Appendix 1- Measures used in this study*}

\section{Leader-Member Exchange (LMX)}

My supervisor is satisfied with my work

My supervisor understands my work problems and needs

My supervisor knows how good I am at my job

My supervisor is willing to use her/his power to help me solve work problems

I have a good working relationship with my supervisor

My supervisor is willing to help me at work when I really need it

I have enough confidence in my supervisor that I would defend and justify his / her decision if he / she were not present to do so

\section{Teamwork}

People I work with resolve disagreements cooperatively

People I work with are cooperative and considerate

People I work with constructively confront problems

People I work with are concerned about each other

When I complete my work tasks, I am happy to help other nurses

\section{Role Ambiguity in relation to patient ${ }^{\#}$}

I am certain which specific nursing strengths I should present to my patients

In my job, I am certain how much service I should provide to my patients

I am certain of what I am expected to do for my patients

\section{Wellbeing}

Overall, I think being a nurse fulfils an important purpose in my work life.

Overall, I get enough time in nursing to reflect on what I do at work

Overall I think I am reasonably satisfied with my work life.

Overall, most days I feel a sense of accomplishment in what I do in nursing

\section{Control - Location of the hospital}

Where are you located: (a) Queensland, (b) NSW (c) Victoria (d) Western Australia?

Demographics

Gender

Age Group

Marital status

Position currently held

*Rated: $\mathrm{SD}=$ Strongly Disagree $\quad \mathrm{DA}=$ Disagree $\quad \mathrm{SE}=$ Slightly Disagree $\mathrm{SL}=$ Slightly Agree $\quad \mathrm{AG}=$ Agree $\mathrm{SA}=$ Strongly Agree

\# Role ambiguity in relation to the patient was reverse scored so a higher score reflects role clarity, whereas a lower score represents role ambiguity. 